\title{
A UML Frame Work for Town and Country Planning
}

\author{
Taskeen Zaidi \\ Deptt of Computer Science \\ B.B. Ambedkar University \\ Lucknow INDIA, 226025
}

\author{
Vipin Saxena \\ Deptt of Computer Science \\ B.B. Ambedkar University \\ Lucknow INDIA, 226025
}

\begin{abstract}
The scientific research problems can be easily modeled by using the modeling language and it is necessary for getting the errors in the solution at the early stages of the development/ implementation of solution of the scientific research problem. Many of the software companies are using the object-oriented modeling language for this purpose. A planning for new town in a country is very complex problem but it can be easily visualized by using the popular object-oriented modeling language known as the Unified Modeling Language (UML). The present work deals with a framework based on the UML model for a new town in the country. The model contains class, use and sequence diagrams.
\end{abstract}

\section{Keywords}

UML, Town and Country Planning, Class Diagram, Use Case Diagram, Sequence Diagram, A Sample Database.

\section{INTRODUCTION}

The planning department is responsible for creation of the master plans for the new town in the country. Introducing a new modern town generally affects the country planning, therefore the design for introducing the new town in the existing planning is necessary and planning of new town is the need of the society. The planning affects the free hold land utilization, impacts of environmental changes, public opinion and affects of society colony. This type of the system consists of the people and building model. On the other side, earthquake affects the planning and many of the towns are suffering due to the earthquake and example in this case earthquakes attacked at Uttarkashi in the year 1991, Latur in the year 1993 and Bhuj in the year 2001 and these are examples of India country which have damaged of lots of property, buildings and also loss of lives. Therefore, In India, in 2004, the Government of India constituted a committee and developed By-Laws and reviewed the town planning in a country. The committee studied the model and observed that there are large areas where town planning legislation and development control/building regulation are not applicable and the sanctioned authority in such areas are either Panchayat in the rural area or Development Commissioner through CPWD/PWD or other such agencies. In some of the cases for change in planning, permission is to be given by the local authorities while in some cases, it is given by the central government of India. Let us describe some of the important references related to the planning of a new town in the country. Many of the organizations have used the remote sensing techniques for proposing the various kinds of designs for development of the areas while some of them also used the designed expert systems for creating the design of the town or modifications in the existing town layout [1]. Remote sensing techniques are described in [2]. Due to evolution of the $3 \mathrm{D}$ modeling, the three dimensional view of the newly developed town are proposed in [3] alongwith the techniques for creation of the three dimensional models. Various kinds of the modeling are proposed by the researchers for planning a new town and one of the important modeling language is the object-oriented modeling language through which one can build the model which will be independent on the programming language are used in the planning to design and develop the land for residential purpose for the people [4]. The notations, symbols used for design are created by the Object Management Group (OMG) and available in [5]. The group is created by the researchers Rambaugh, Booch and Jacobson [6-8]. The various kinds of diagrams can be used for modeling purpose of the development of new town and overall country planning.

The present work is based upon the modeling for the new town in a country. An object oriented technique is used for modeling purpose, UML class, use case and sequence diagrams are designed for showing the static and dynamic behavior of the system. A sample database is also created in the form of table.

\section{UML CLASS MODEL FOR TOWN PLANNING}

The main purpose of a class diagram is to represent the static behavior of the research problem. It is a pictorial representation in the form of object-oriented which has attributes, operations and the relationships between the objects. In the following UML class diagram, town planning shows the ten major classes alomgwith the aggregation. Initially Administrator class is responsible for the creation of the user accounts and controlled by the User class, thereafter user logins the account through Login and Password class and then various inputs for the town planning may be given by the users to see the location of the area. The Town_Input class is further aggregated through the various sub classes as per the categorization of the areas of the town and the important classes are the Agriculture_area, Buisness_area, Residential_area and Land_area and these classes are finally connected to the class Planning_deptt. The planning department has the complete information about the various areas in the town and user can see all these information by giving the input database. 


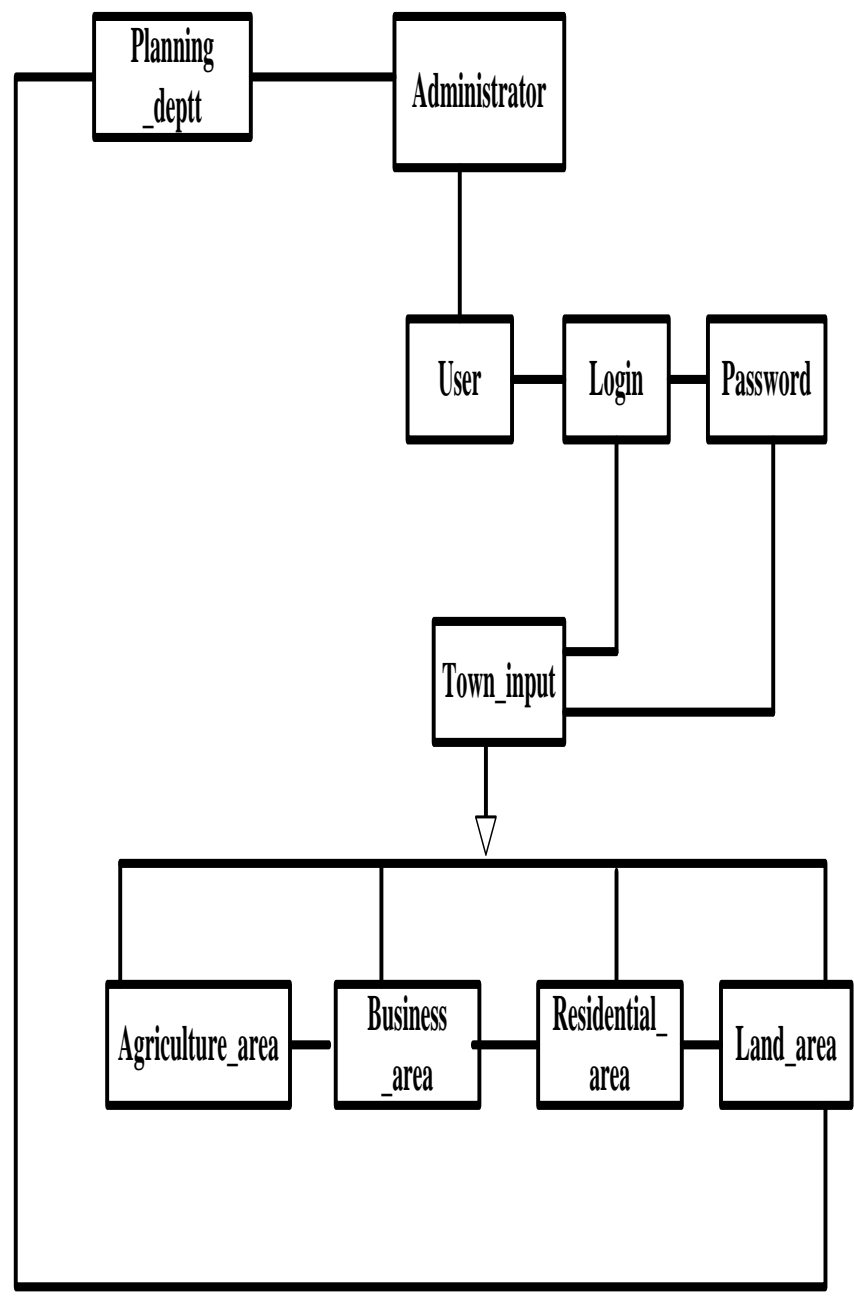

Fig. 1: UML class representation of town planning

\section{UML USE CASE MODEL}

It is a pictorial representation which contains actors who are performing the various action on the system. The use case diagram is very useful for the stakeholder to understand the system. Use Case diagram is designed to capture the dynamic representation of a system. It gathers the requirements of a system including internal and external effects. So when the system are analyzed its functionalities, actors are identified and use cases are prepared. UML use case is used to represent the relationship between actor and use case. The following figure 2 represents the use case diagram for giving the desired inputs for checking the various locations. The diagram contains two actors User and Administrator, User can login, change the password and check the inputs for the various locations while the Administrator can update the user information and both the actors can see the report generated.

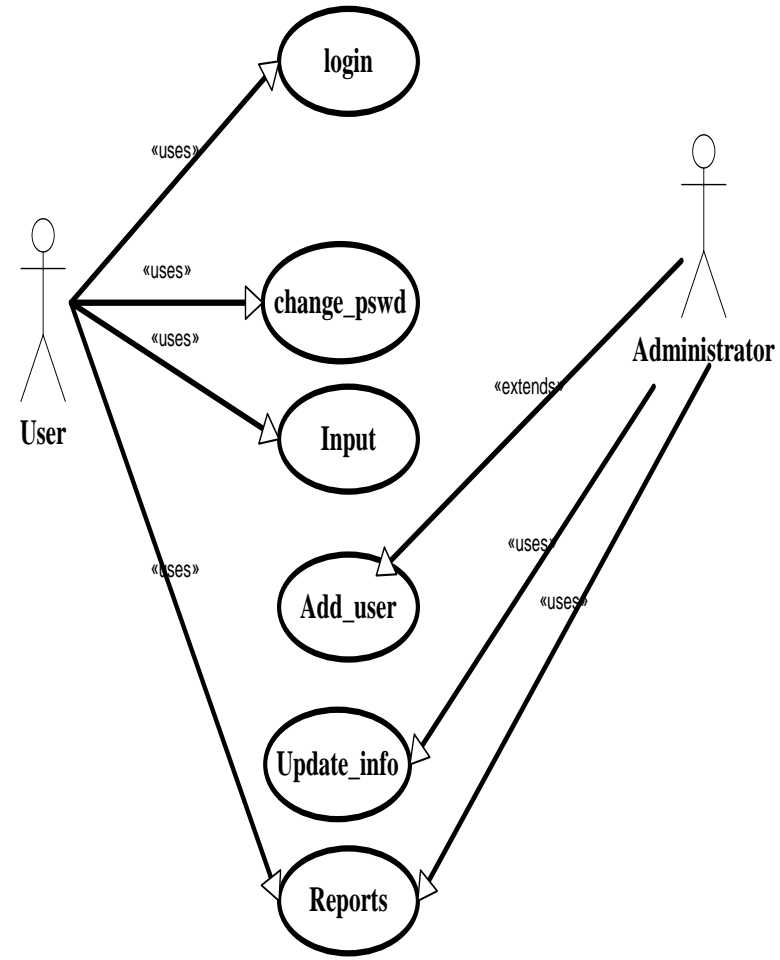

Fig. 2: UML use case diagram

\section{DESIGN OF OBJECT-ORIENTED DATABASE}

Limited work in the literature is available on the object oriented database therefore Unified Modeling Language (UML) which is platform independent language supports the object oriented database by considering the different attributes. For the Town_input class from figure 1 contains the various kinds of the object-oriented database as given in the following table:

Table 1: A sample database for town planning (table name:sample_database)

\begin{tabular}{|l|l|l|l|}
\hline $\begin{array}{l}\text { Agriculture } \\
\text { _area_code }\end{array}$ & $\begin{array}{l}\text { Business_area } \\
\text { _code }\end{array}$ & $\begin{array}{l}\text { Residential_} \\
\text { area_code }\end{array}$ & $\begin{array}{l}\text { Land_area_ } \\
\text { code }\end{array}$ \\
\hline 213 & 324 & 567 & 786 \\
\hline 312 & 768 & 587 & 987 \\
\hline 432 & 457 & 876 & 560 \\
\hline 564 & 654 & 785 & 432 \\
\hline
\end{tabular}

On the above database one can generate the different queries and some of them are described below in brief: 
Sample query-I:

Select Agriculture_area_code from sample_database where Land_area_code $=$ "987"

The output of the above query is the following row of the table:

\begin{tabular}{|l|l|l|l|}
\hline 312 & 768 & 587 & 987 \\
\hline
\end{tabular}

The above sample data is very small, however it can be extended for large database and in a few seconds, one can search the desired database.

\section{CONCLUDING REMARKS}

. From the above, one can conclude that UML is a platform independent powerful modeling language and one can design the large object-oriented database from which user can search the desired database in a minimum time period. The above proposed UML model can be implemented in any objectoriented programming language with supporting backend database. The work can be extended for the design of three dimensional data cubes for storing the large database and user can perform the three dimensional queries on the data cubes

\section{REFERENCES}

[1] Aniati Murni, Hardianto, siti Nurbaya, "The Use of Remote Sensing Techniques and Expert system in Regional Planning", IEEE 1999 pg 619-621.

[2] Alexandr Zhuykov, Ljudmila Sarycheva, "Cluster Analysis of Territories by the Totality of Ecological and Socio-Economic Indices, IEEE 2001, pg 1971-1972.

[3] Katija Ewald, Volker Coors, "Appraisal of standards for 3D City Models", Ninth International Conference on Information Visualization 2005.

[4] Oleg V. Stakheev, "Language of Modeling of TownPlanning Situations”, IEEE 2004 pg 349-350.

[5] OMG, Unified Modeling Language Specification, Available Online via http://www.omg. org 2001 (Accessed on 12 Feb. 2013).

[6] G. Booch, Benjamin Cummings, Object Oriented Analysis and Design, 1994.

[7] G. Booch, (2002), Growing the UML Software and System Modeling, Vol. 1, No. 2, pp. 157-160, December, 2002.

[8] G. Booch, Object Solutions: Managing the Object Oriented Project, ISBN-0-8053-0594-7 